\title{
Análise do nível de estresse do profissional de Contabilidade
}

\section{Analysis of stress level of accounting professional}

\section{Simone Silva da Cunha Vieira}

Doutora em Controladoria e Contabilidade pela Universidade de São Paulo

Professora do Mestrado em Ciências Contábeis da Universidade do Estado do Rio de Janeiro

Endereço: Rua São Francisco Xavier, 524, $9^{\circ}$ andar, Bloco E, Maracanã

CEP: 20550-013 - Rio de Janeiro/RJ - Brasil

E-mail: simoneantonio@uol.com.br

Telefone: (21) 2334-0217

\section{Francisco José dos Santos Alves}

Doutor em Controladoria e Contabilidade pela Universidade de São Paulo

Coordenador do Mestrado em Ciências Contábeis da Universidade do Estado do Rio de Janeiro

Endereço: Rua São Francisco Xavier, 524, $9^{\circ}$ andar, Bloco E, Maracanã

CEP: 20550-013 - Rio de Janeiro/RJ - Brasil

E-mail: fjalves@globo.com

Telefone: (21) 2334-0927

\section{Farid Succar Junior}

Mestre em Ciências Contábeis pela Universidade do Estado do Rio de Janeiro

Endereço: Rua São Francisco Xavier, 524, $9^{\circ}$ andar, Bloco E, Maracanã.

CEP: 20550-013 - Rio de Janeiro/RJ - Brasil

E-mail: faridsj@gmail.com

Telefone: 55 (21) 2334-0927

Artigo recebido em 20/03/2012. Revisado por pares em 17/08/2012. Reformulado em 10/10/2012. Recomendado para publicação em 07/11/2012 por Sandra Rolim Ensslin (Editora Científica). Publicado em 14/12/2012. 


\title{
Resumo
}

Este artigo tem o objetivo de identificar o grau e os sintomas de estresse que ocorrem nos profissionais de Contabilidade, relacionando-os com fatores individuais e profissionais. $\mathrm{Na}$ revisão da literatura, procurou-se discutir os conceitos sobre estresse, suas fases e sintomas. Utilizou-se o modelo de estresse desenvolvido por Lipp (2003), efetuando a análise descritiva e estatística com uso do Microsoft Excel e SPSS. Os resultados encontrados foram: $50 \%$ não apresentam estresse; $35 \%$ encontram-se na fase de resistência; $13 \%$ em exaustão. Em suma, o estresse dos contabilistas é similar e aproxima-se do apresentado na literatura; os sintomas predominantes foram os físicos.

Palavras-chave: Contabilistas. Estresse. Homens. Mulheres.

\begin{abstract}
This article aims to identify the degree and symptoms of stress that occur in accounting professionals, relating them with individual and professional factors. In reviewing the literature we attempted to discuss the concepts of stress, its phases and symptoms. We used the stress model developed by Lipp (2003), performing the descriptive and statistical analysis using Microsoft Excel and SPSS. The results were: 50\% of the professionals have no stress; $35 \%$ are in the resistance phase; and $13 \%$ are in exhaustion. In short, the stress of accountants is similar and approaches the presented in the literature; the predominant symptoms were the physical ones.
\end{abstract}

Keywords: Accountants. Stress. Men. Women.

\section{Introdução}

A sociedade atual passa por diversas mudanças políticas e sociais (WISNIEWSKI; STEFANO, 2008). Os indivíduos são submetidos a vários tipos de pressão, tanto no campo corporativo quanto no pessoal. Para Ferachin et al. (2004), o ritmo competitivo da sociedade leva o cidadão ao estresse. Segundo a Organização das Nações Unidas, o estresse é conhecido como o "mal do século"; já para a Organização Mundial de Saúde é uma epidemia que afeta mais de $90 \%$ da população mundial (SILLAS, 2011). De acordo com Ana Maria Rossi, presidente da International Stress Management Association ISMA Brasil, "cerca de $70 \%$ da população apresenta algum nível de estresse" (SILLAS, 2011, p. 14). Para Passati e Dias (2002), as pesquisas sobre estresse têm justificativa em virtude do alto custo para as empresas.

O tema estresse apresenta poucas pesquisas e trabalhos empíricos publicados na área de Ciências Contábeis no Brasil. Este estudo tem a intenção de promover o interesse por essa área, pois a qualidade e o bom desempenho do trabalho podem ser prejudicados caso o profissional esteja estressado. O estresse pode fazer com que o contabilista cometa erros que possam vir a gerar multas. Essa questão torna-se relevante quando se observam 
as mudanças em virtude da adoção dos padrões contábeis Internacionais de Contabilidade do IASB, Lei n. 6.404, de 1976. Portanto, caso um indivíduo esteja com estresse, ele pode perder desempenho e cometer erros, prejudicando a instituição na qual trabalha. Mas, se não estiver estressado, ele pode desempenhar sua tarefa da melhor forma possível, de forma correta.

Os estudos apresentados no referencial teórico ajudam os pesquisadores na busca pelo conhecimento sobre a realidade, pois afeta muitos trabalhadores em todo o mundo, independente da profissão. Nesse contexto, o estudo pretende identificar o grau de estresse e os sintomas fundamentais que ocorrem nos profissionais de Contabilidade, relacionando-os com fatores individuais e profissionais em seu desempenho e os sintomas de estresse que apresentam. Para relacionar a teoria à prática, utilizou-se no questionário o modelo quadrifásico de estresse de Lipp, Inventário de Sintomas de Stress de Lipp (ISSL), com o objetivo de analisar e detectar problemas que possam existir no ambiente familiar ou no profissional e definir os sintomas de estresse em físicos e psicológicos. Este estudo está dividido nas seguintes seções: revisão da literatura, aspectos teóricos e conceituais; metodologia da pesquisa; apresentação e discussão dos resultados; e, por fim, as considerações finais.

\section{Referencial Teórico}

Até o século XVII, o estresse era utilizado na literatura inglesa com o significado de aflição e adversidade (LIPP, 2003). Já no século XVIII, utilizou-se como sinônimo de sofrimento e privação. Na década de 1920, o trabalho de Hans Selye definia stress como resposta do corpo a qualquer exigência. Lipp e Malagris (2001) definem estresse como defesa do organismo que ocorre quando uma pessoa se confronta com uma situação irritante ou de pura felicidade.

Selye (1965) concluiu que o estresse é constituído de três fases: alerta, resistência e exaustão. Lipp (2000) identificou a fase de quase exaustão, localizada entre as fases de resistência e exaustão. O modelo quadrifásico é dividido, segundo Lipp (2003), em:

- Fase de alerta: O ser humano se desequilibra internamente. É possível observar 15 sintomas, sendo 12 físicos e três psicológicos. Segundo Peres (2008), os principais sintomas são: elevação da frequência cardíaca, cefaleia, sensação de esgotamento e insônia. Uma pessoa estará nessa fase de estresse se apresentar nas últimas 24 horas mais de cinco sintomas.

- Fase de resistência: Os indivíduos podem apresentar 15 sintomas de estresse na semana, 10 físicos e cinco psicológicos. Os sintomas da primeira fase são mais frequentes. Na fase de resistência, o sujeito apresenta mais de três e menos de nove sintomas.

- Fase de quase exaustão: Por não conseguir se restabelecer internamente, o humor das pessoas varia entre bons e maus momentos. A inclusão do indivíduo na fase de estresse de quase exaustão é definida quando o sujeito apresenta nove ou mais sintomas semanais apresentados na fase de Resistência.

- Fase de exaustão: Nesta fase há 23 sintomas, sendo 11 físicos e 12 psicológicos. Sintomas como depressão e irritabilidade são destaques. Nessa etapa, segundo Lipp 
(2000), o organismo está exaurido tanto fisicamente quanto psicologicamente. Um indivíduo está nessa fase se apresentar acima de nove sintomas mensais.

O estresse no ambiente profissional interfere na qualidade de vida, provocando problemas familiares e sociais (LIMONGI-FRANCA; RODRIGUES, 1999). Smith et al. (2000) associam o aumento do estresse a fatores demográficos e ocupacionais. Para eles o estresse mais elevado está associado a trabalhadores viúvos ou separados, independente do gênero. O Centro Psicológico de Controle de Estresse analisou 915 funcionários de escritórios contábeis de empresas paulistas (SILLAS, 2011). Dos entrevistados 40\% tinham algum sintoma de estresse, $38 \%$ eram homens e $46 \%$, mulheres.

Segato et al. (2010) realizaram um estudo do estresse psicológico com 31 velejadores de alto nível esportivo. As atletas apresentaram níveis de estresse mais elevados que os homens. Romero, Oliveira e Nunes (2008) estudaram o estresse no ambiente organizacional. Os resultados apontam que, para o sexo masculino, os níveis de estresse distribuem-se de forma equivalente: $31,3 \%$ apresentaram nível baixo de estresse, $37,5 \%$ nível médio e 31,3\% nível alto. Já nos resultados para o sexo feminino, observa-se um elevado percentual no nível médio de estresse. Takahashi (2009) analis ou a avaliação da vulnerabilidade ao estresse no trabalho de operadores de telemarketing. O estresse foi maior nas mulheres, 59\%; enquanto os homens obtiveram $32,3 \%$.

Rossi (2005) pesquisou 586 profissionais da área de saúde: 220 homens e 366 mulheres. Para os homens, os principais estressores foram: a incerteza, o estresse interpessoal, a sobrecarga de trabalho e a dificuldade em administrar o tempo; já para as mulheres os principais fatores foram a sobrecarga de trabalho, a incerteza, a incapacidade de administrar o tempo e o estresse interpessoal. Lipp e Tanganelli (2002) realizaram estudo sobre a qualidade de vida em magistrados da Justiça do Trabalho. A análise dos dados revelou que, da amostra, a grande maioria se encontrava na fase de resistência do estresse $(68 \%)$.

Para Scarparo et al. (2008), ao vincularem o estresse ocasionado pelo vestibular em jovens e adultos novos, concluíram que as mulheres sofrem mais estresse que os homens. Para confirmar, Rossetti et al. (2008) observaram maior incidência de estresse no sexo feminino (59\%) do que no masculino (32,3\%) nos funcionários da Polícia Federal de São Paulo. Na pesquisa de Milsted, Amorim e Santos (2009), a maior parte dos participantes $(65,47 \%)$ encontrava-se na fase de resistência, e $34,52 \%$, na fase de exaustão.

Sillas (2011) efetuou uma pesquisa em que analisou o nível de estresse das profissionais contabilistas atuantes no estado do Paraná por meio da utilização do Inventário de Sintomas de Estresse para Adultos (ISSL) de Lipp (1998). Obteve uma amostra de 202 respondentes, das quais $69,79 \%$ estão enquadradas em uma das fases de estresse, a maior parte está localizada nas fases de resistência e de exaustão.

\section{Metodologia da Pesquisa}

Esta seção aborda os procedimentos metodológicos, apresenta o tipo e o método de pesquisa, a população e a amostra, a coleta e a análise de dados. 


\subsection{Tipo e método de pesquisa}

A pesquisa exploratória tem por objetivo conhecer a variável de estudo tal como se apresenta, seu significado e o contexto onde ela se insere. Esse tipo permite o controle dos efeitos desvirtuadores da percepção do pesquisador, permite que a realidade seja percebida tal como ela é, e não como o pesquisador pensa que seja.

Nesse sentido, a pesquisa exploratória leva o pesquisador à descoberta de enfoques, de percepções e de terminologias novas, contribuindo para que seu próprio modo de pensar seja modificado. O estudo exploratório, portanto, alia as vantagens de se obterem os aspectos qualitativos das informações à possibilidade de quantificá-los posteriormente (PIOVESAN; TEMPORINI, 1995).

\subsection{População e Amostra}

A população em questão constitui-se de contabilistas registrados no cadastro do Conselho Regional de Contabilidade do Estado do Rio de Janeiro (CRC-RJ). De acordo com informações obtidas no sítio do Conselho Federal Contabilidade (2011), existem 291.727 homens e 203.857 mulheres contabilistas no Brasil. Dos contabilistas registrados no CRC-RJ, 31.560 são homens e 21.405 são mulheres. Portanto, esse é o número da população investigada no presente trabalho.

Nesta pesquisa, utilizou-se um pacote de aplicativos do Google. O Google Docs foi utilizado para estruturar o Questionário de Pesquisa adaptado do Inventário de Sintomas de Stress de LIPP (ISSL) e do questionário utilizado por Sillas (2011). E-mais foram enviados para o Conselho Regional de Contabilidade (<comunicacao@boletimcrcrj.org.br>) contendo a carta de apresentação e explicando os objetivos da pesquisa. O questionário foi disponibilizado no sítio da Internet ("Níveis de Estresse dos Contabilistas do Estado do Rio de Janeiro". <https://spreadsheets.google.com/spreadsheet/viewform?formkey=dHoxbUFDOGFuSEdPU nQ1NW1vYnZZRnc6MQ>) do dia 15 de julho de 2011 até o dia 5 de setembro de 2011; sendo recebidas 445 respostas, oriundas de oito regiões fluminenses diferentes. Dois desses questionários foram descartados da análise por não estarem preenchidos em totalidade. Assim, ao final, foi obtida uma amostra não intencional de 443 contabilistas. As respostas dos questionários foram analisadas de forma confidencial e os resultados foram apresentados e utilizados apenas com o propósito de pesquisa.

Desses 443 respondentes, a idade variou entre 18 e 65 anos, sendo 241 (54\%) do sexo feminino e 202 (46\%) do sexo masculino. Os participantes foram classificados em subgrupos, com o pressuposto de que há uma demanda diferente com relação a estudo e trabalho nessas faixas etárias e que podem ser possíveis Dados da Pesquisa de Estresse (ROSSETTI et al., 2008).

\subsection{Procedimento para Coleta e Análise dos Dados}

Em 1994, Lipp e Guevara validaram o Inventário de Sintomas de Stress para Adultos (ISS). Em 2000, esse instrumento foi aprimorado e recebeu o título de Inventário de Sintomas de Stress para Adultos de Lipp (ISSL) e possibilita um diagnóstico de estresse (LIPP; MALAGRIS, 2001). 
A diferença entre os inventários é bastante simples. O ISS separava o processo de estresse em três fases: alerta, resistência e exaustão (trifásico). Já o ISSL apresenta um modelo quadrifásico do estresse. Lipp (2000) define os sintomas de estresse em dois grupos: físicos e psicológicos. No Quadro 1, apresenta-se uma síntese das fases que compõem o modelo de Lipp.

\begin{tabular}{|c|c|c|c|}
\hline \multirow{2}{*}{$\begin{array}{ll}\text { Fases } & \text { de } \\
\text { Estresse } & \\
\end{array}$} & \multirow{2}{*}{$\begin{array}{l}\text { Quantidade de } \\
\text { Sintomas } \\
\end{array}$} & \multicolumn{2}{|c|}{ Número de Sintomas } \\
\hline & & Físicos & Psicológicos \\
\hline Alerta & $x>5$ & 3 & 12 \\
\hline Resistência & $3<x>9$ & 5 & 10 \\
\hline Quase Exaustão & $x>8$ & 5 & 10 \\
\hline Exaustão & $x>9$ & 11 & 12 \\
\hline
\end{tabular}

Fonte: Elaborado pelos autores.

- Para que um indivíduo se enquadre na fase de alerta é necessário que este apresente no mínimo seis sintomas. Caso não atinja esse número, será considerado sem estresse.

- Para que um indivíduo se enquadre na fase de resistência é necessário que apresente no mínimo quatro e no máximo oito sintomas. Caso não atinja o mínimo de quatro, será considerado sem estresse. Caso apresente mais de oito sintomas, estará na fase de quase exaustão do estresse.

- Para que um indivíduo se enquadre na fase de exaustão é necessário que este apresente no mínimo 10 sintomas. Caso não atinja esse número, será considerado sem estresse.

Conforme Marconi e Lakatos (1985), questionário é uma forma de obter dados e informações. "Questionários são documentos que perguntam as mesmas questões para todos os indivíduos da amostra" (VIEIRA, 2009, p. 82). Para Richardson (1999, p. 209-200), "questionários cumprem duas importantes funções na pesquisa, descrever características e de medir determinadas variáveis".

Para obter informações foi estruturado o questionário no Google Docs, sendo composto por questões fechadas, exceto "idade" e "tempo na Contabilidade". O questionário foi dividido em três partes:

- Fatores Profissionais: Nesta parte, dividem-se os respondentes por regiões do estado do Rio de Janeiro (metropolitana, litorânea, serrana, costa verde, norte, noroeste, médio paraíba e centro-sul); renda familiar em salários mínimo $(<1,1$ a 5, 6 a 10, 11 a 15,16 a 20, > 20); tempo de atuação na Contabilidade (em anos); papel de atuação na Contabilidade (proprietário de escritório de Contabilidade, colaborador de escritório, colaborador em empresa privada, colaborador em empresa pública, colaborador em empresa do terceiro setor, professor de Contabilidade, outros); principais atividades na Contabilidade (auditoria, controladoria, tributária, perícia, fiscal, Contabilidade pública, professor(a) de Contabilidade, outros) e se desempenham ou não atividades extras.

- Fatores Individuais: Nesta parte, dividem-se os respondentes entre os gêneros; idades; estado civil (casado(a), viúvo(a), solteiro(a); união estável, separado(a)/divorciado(a)); possuem ou não filhos; atividades domésticas em horas diárias (zero, até duas, entre duas e quatro, acima de quatro); relacionamento social 
(muito insatisfeito, insatisfeito, nem satisfeito nem insatisfeito, satisfeito, muito satisfeito); tempo pessoal (nunca, muito pouco, às vezes, muito tempo, sempre).

O Microsoft Excel 2007® foi utilizado para tabulação dos dados e realização da Análise Exploratória de Dados (AED). De acordo com Hair Jr. et al. (2005), embora ignorada por alguns pesquisadores, a AED é de suma importância, porque leva a uma visão crítica das características dos dados. Houve a verificação do relacionamento entre os níveis de estresse apresentados pelos respondentes e seus aspectos individuais e profissionais. Para isso, optouse pela utilização da técnica de Análise de Correspondência (AC), com auxílio do SPSS 8.0, programa utilizado para realizar o cruzamento de dados entre as diversas variáveis.

A AC é uma técnica estatística multivariada de caráter exploratório e descritivo (ARANHA et al., 2004). Para Hair Jr. et al. (2009, p. 36), a AC emprega uma tabela de contingência, que é a tabulação cruzada de duas variáveis categóricas, transforma os dados não métricos em um nível métrico e faz redução dimensional e mapeamento perceptual. Para Sillas (2011), a AC caracteriza-se como uma importante ferramenta analítica de dados categóricos. Portanto, o objetivo é investigar qual a relação dos diferentes níveis de estresse com os aspectos individuais e profissionais.

\section{Apresentação e Discussão dos Resultados}

Esta seção aborda as características individuais, profissionais, as fases e os sintomas de estresse que afetam aos profissionais de Contabilidade respondentes da pesquisa.

\subsection{Aspectos Individuais}

Buscou-se avaliar os aspectos individuais como: gênero, idade, estado civil, número de filhos, tempo com atividades domésticas e os cuidados pessoais, relacionamento pessoal, lazer e entretenimento. Os respondentes são 202 homens e 241 mulheres, com idade média de 33,4 anos, 85\% tendo até 40 anos. A maioria pertence à classe dos casados, com 46,5\% da amostra; os solteiros com 37,5\%; além disso, $60 \%$ não têm filhos e $62 \%$ dos respondentes gasta até duas horas diárias com suas atividades domésticas. Isso demonstra que os respondentes têm pouco ou nenhum tempo para seus afazeres domésticos.

\subsection{Aspectos Profissionais}

Questionou-se a renda familiar mensal, o tempo de atuação na profissão, o papel e as funções que os respondentes desempenham no trabalho, distribuição demográfica e se realizam ou não atividades complementares. A maior parte dos respondentes, $56 \%$, recebe mais de 10 salários mínimos, $75 \%$ possuem até 10 anos de atuação na profissão contábil e $74 \%$ realizam atividades contábeis complementares àquela principal. As principais atividades desempenhadas na Contabilidade foram controladoria (21\%) e Contabilidade Pública (19\%), e a maior parte das pessoas trabalha na região metropolitana do estado do Rio de Janeiro (68\%).

\subsection{Fases e Sintomas de Estresse}


Procurou-se identificar as fases e os sintomas de estresse dos profissionais contabilistas respondentes. Constata-se que 50\% dos respondentes não se enquadram em nenhuma das quatro fases de estresse, 104 homens e 119 mulheres; a fase de resistência com $35 \%$ dos respondentes, 76 homens e 78 mulheres; seguido da fase de exaustão com 13\%, 19 homens e 41 mulheres; e as fases de alerta e quase exaustão apresentaram apenas $1 \%$ das respostas válidas. Na Tabela 1, são apresentados os sintomas físicos e psicológicos divididos por fase.

Tabela 1 - Sintomas e Fases de Estresse

\begin{tabular}{c|c|c|c|c|c|c|c|c|c|c}
\hline Sintomas & $\begin{array}{c}\text { Sem } \\
\text { estresse }\end{array}$ & $\%$ & Alerta & $\%$ & Resistência & $\%$ & $\begin{array}{c}\text { Quase } \\
\text { exaustão }\end{array}$ & $\%$ & Exaustão & $\%$ \\
\hline Físicos & 947 & $82 \%$ & 17 & $85 \%$ & 906 & $71 \%$ & 22 & $69 \%$ & 588 & $42 \%$ \\
\hline Psicológicos & 119 & $10 \%$ & 3 & $15 \%$ & 365 & $29 \%$ & 10 & $31 \%$ & 811 & $58 \%$ \\
\hline Nenhum & 93 & $8 \%$ & 0 & $0 \%$ & 0 & $0 \%$ & 0 & $0 \%$ & 0 & $0 \%$ \\
\hline Total & 1159 & $100 \%$ & 20 & $100 \%$ & 1271 & $100 \%$ & 32 & $100 \%$ & 1399 & $100 \%$ \\
\hline
\end{tabular}

Fonte: Dados da pesquisa.

$\mathrm{Na}$ pesquisa em questão, os contabilistas classificados em quase todas as fases de estresse, exceto na fase de exaustão, apresentam maior frequência do número de sintomas físicos do que psicológicos. Esses resultados estão de acordo com as pesquisas de Lipp e Tanganelli (2002) e a de Milsted, Amorim e Santos (2009).

\subsection{Níveis de estresse e os aspectos individuais e profissionais}

Neste item, houve a agregação entre as fases de estresse e os diferentes aspectos pessoais e profissionais dos contabilistas do estado do Rio de Janeiro. Para isso, foi feito uso da técnica estatística denominada Análise de Correspondência. O primeiro aspecto abordado nessa análise foi a relação entre o gênero e o estresse, conforme Gráfico 1. As mulheres apresentam maior proximidade dos sem estresse, e o sexo oposto apresenta-se mais próximo das fases de resistência e alerta.

\section{Gráfico 1 - Fases de Estresse x Gênero}

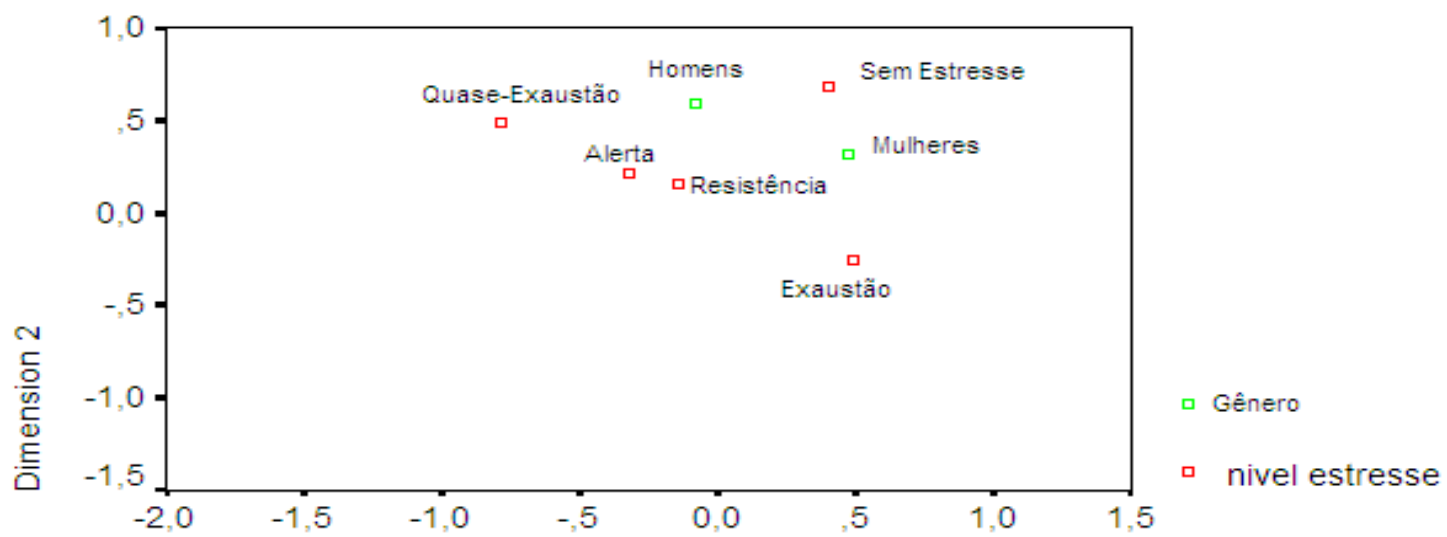

Dimension 1

Fonte: Dados da pesquisa. 
No Gráfico 2, as fases de estresse são analisadas com as faixas etárias. Considerando os profissionais sem estresse, pode-se observar que predominam os contabilistas com idade entre 26 e 35 anos. A fase de resistência apresenta proximidade com idade entre 41 a 45 anos, e, acima de 46 anos, os contabilistas apresentam-se próximos da fase de exaustão. Nesse último ponto, essa pesquisa equipara-se a de Sillas (2011), pois também foi constatado que as mulheres contabilistas com mais de 46 anos encontram-se na fase de exaustão.

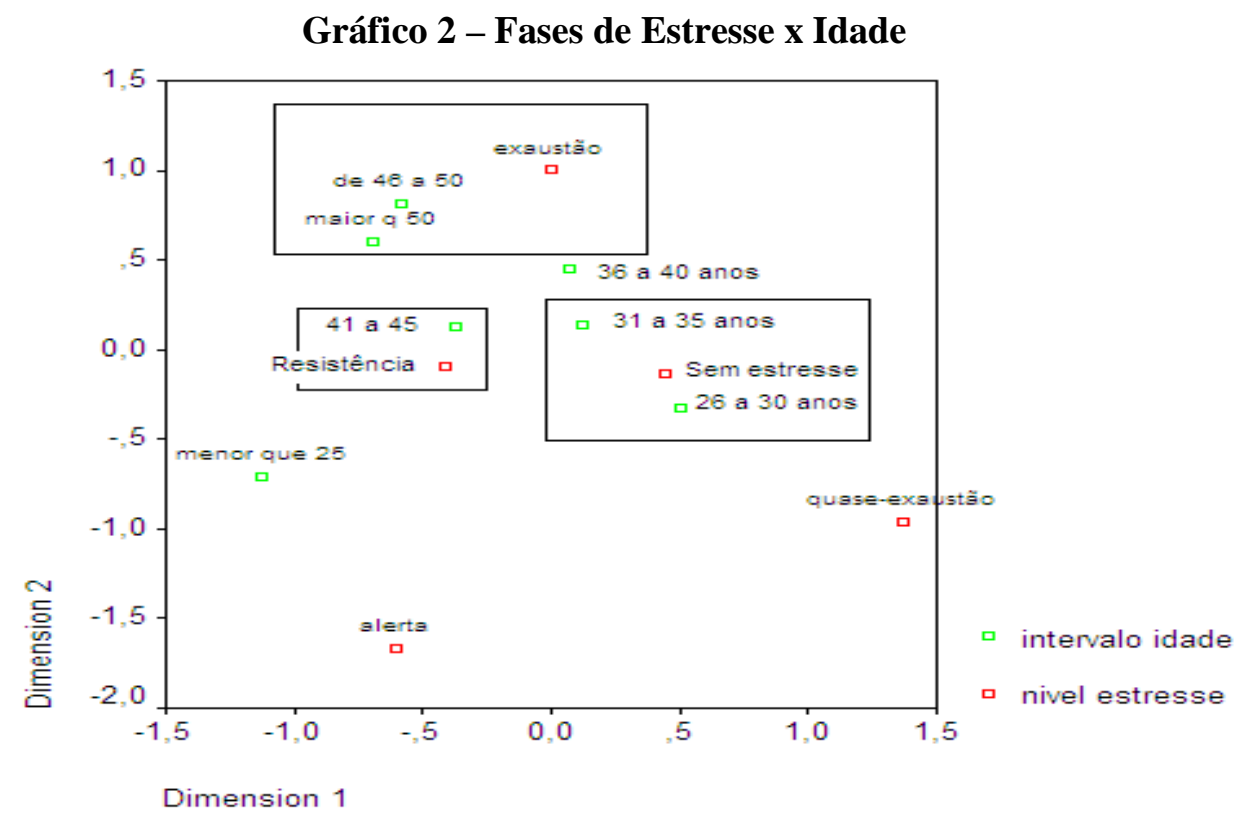

Fonte: Dados da pesquisa.

O Gráfico 3 é a análise entre as fases de estresse e o estado civil. Os contabilistas separados se aproximam da fase de exaustão. Os casados e os em união estável figuram entre os grupos que se encontram na fase de resistência. Já na pesquisa de Sillas (2011), os casados ou estão na fase de resistência ou na de exaustão.

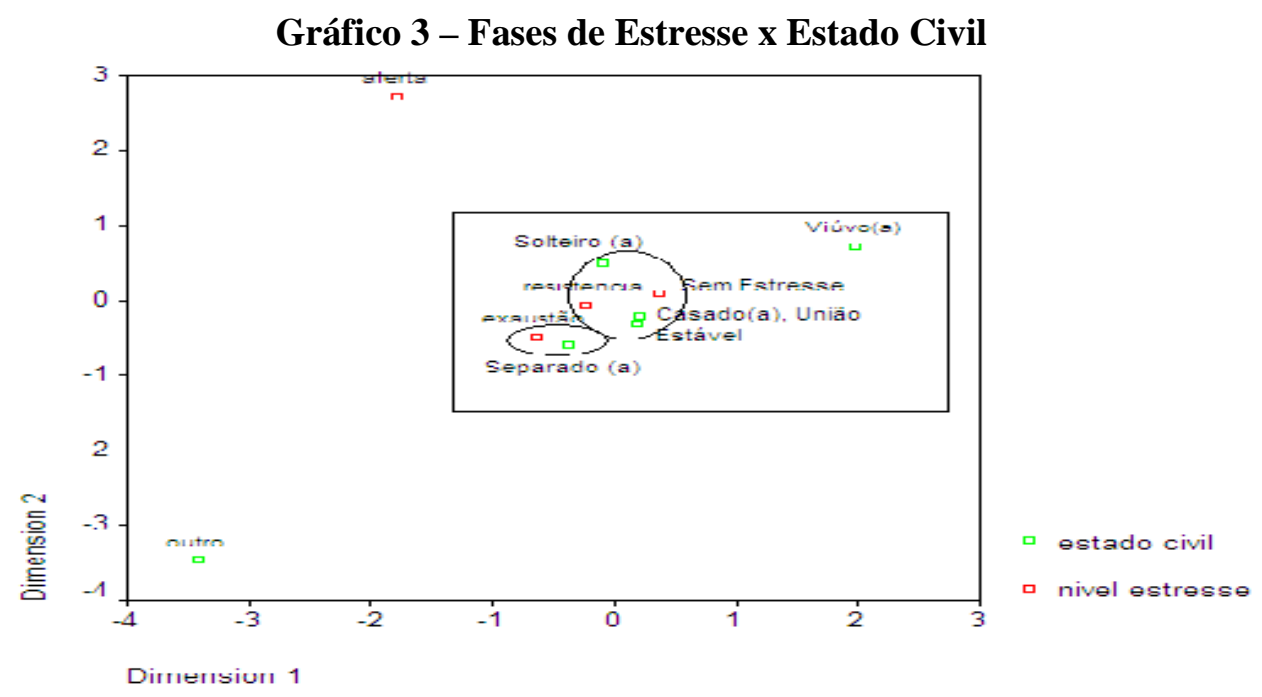

Fonte: Dados da pesquisa. 
No Gráfico 4, os que não possuem filhos estão próximos à fase de resistência ou não apresentam estresse. Já aqueles que responderam possuir filhos estão próximos às fases de alerta e de quase exaustão.

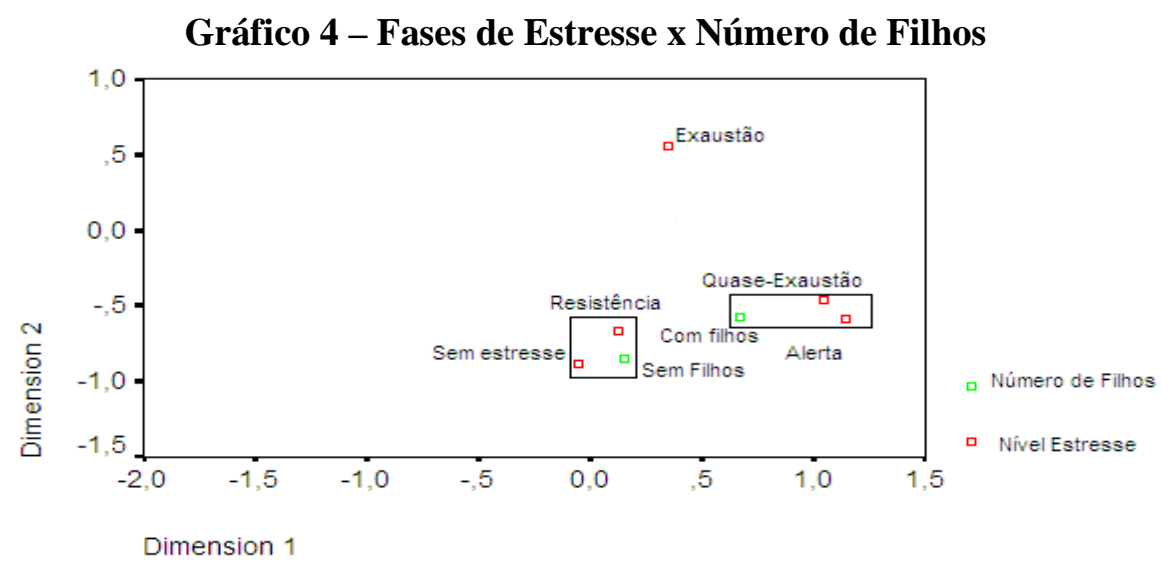

Fonte: Dados da pesquisa.

O Gráfico 5 demonstra a relação entre as atividades domésticas e as fases de estresse. Os respondentes que gastam até duas horas com as tarefas domésticas não apresentam estresse; já aqueles que gastam mais de duas horas diárias encontram-se na fase de resistência. Já na pesquisa de Sillas (2011), os respondentes que gastam mais de duas horas em atividades domésticas estão na fase de quase exaustão e de exaustão.

\section{Gráfico 5 - Fases de Estresse x Tempo Dedicado a Atividades Domésticas}

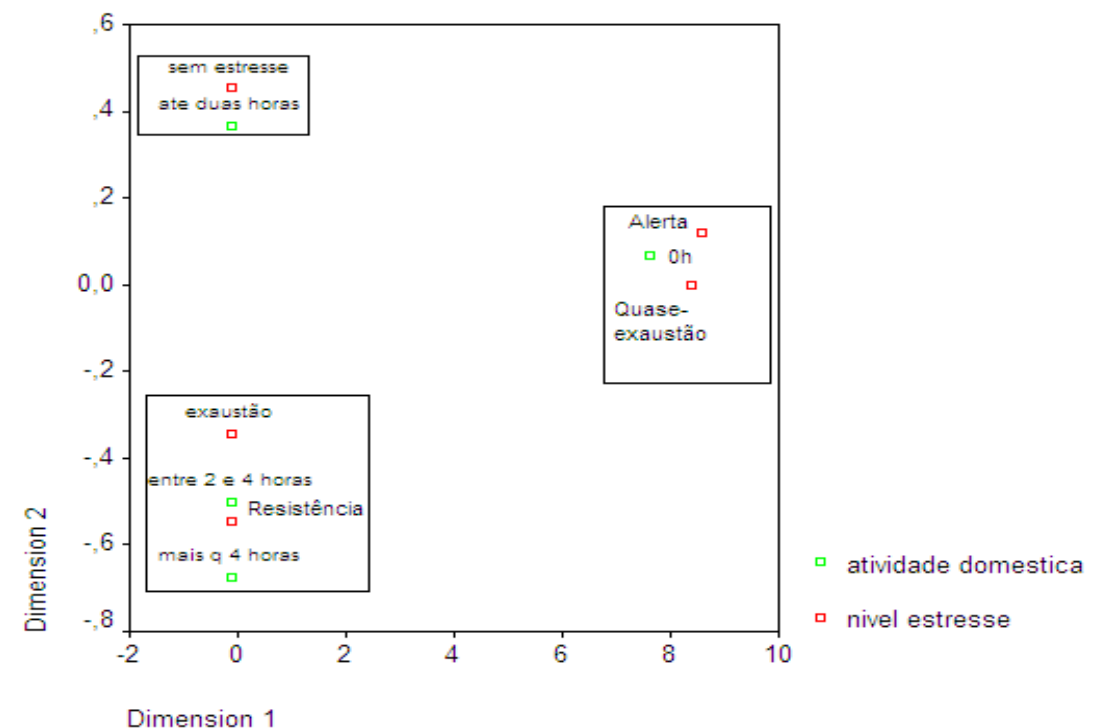

Fonte: Dados da pesquisa.

O Gráfico 6 evidencia o tempo que os respondentes reservam a cuidados pessoais. Os indivíduos que nunca têm tempo encontram-se próximos à fase de exaustão, aqueles que têm 
muito pouco tempo encontram-se perto da fase de resistência; os profissionais que, às vezes, têm tempo são enquadrados ou na fase sem estresse ou na fase de alerta.

Gráfico 6 - Fases de Estresse x Tempo Dedicado a Cuidados Pessoais

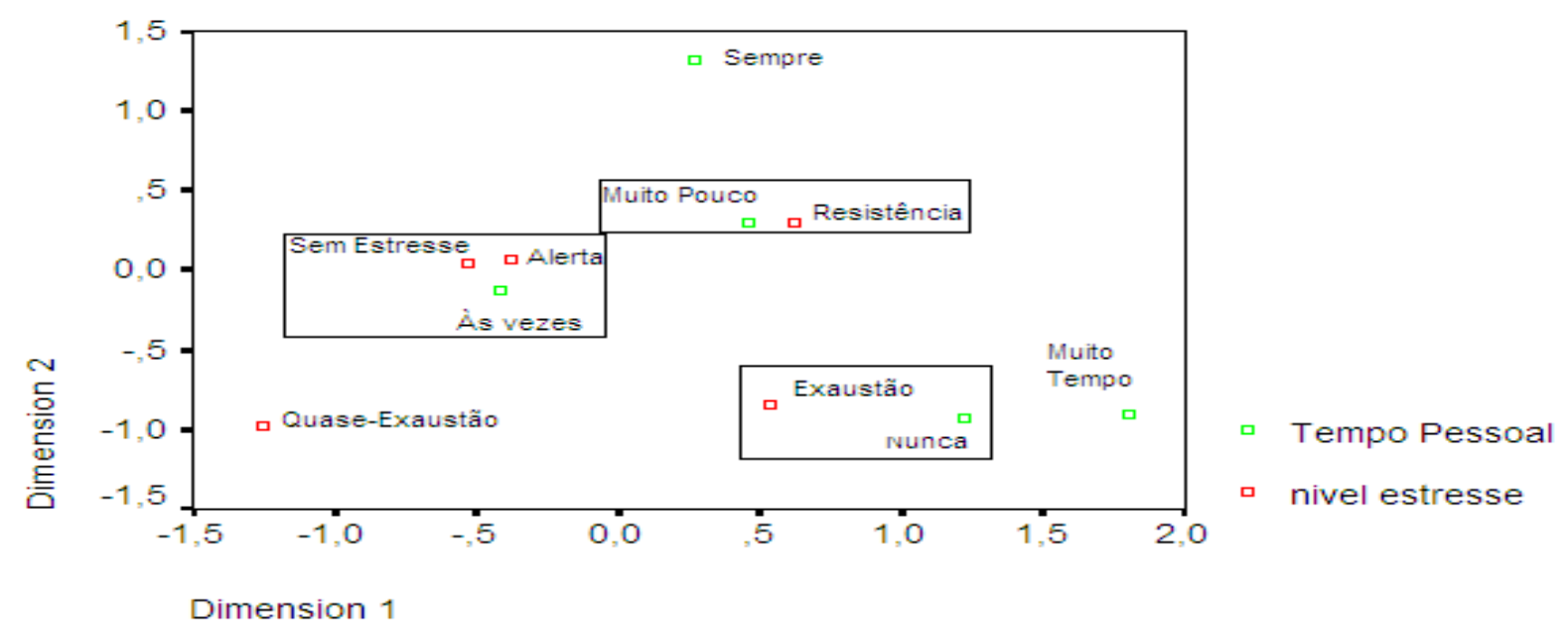

Fonte: Dados da pesquisa.

O Gráfico 7 analisa a renda dos contabilistas com a fase de estresse. Renda de 1 a 5 salários (fase de resistência); renda entre 5 a 15 salários (fase de alerta); de 15 a 20 salários (fases de quase exaustão e exaustão) e, por fim, aqueles que recebem mais de 20 salários não se enquadram em nenhuma das fases de estresse. A pesquisa de Sillas (2011) diverge nesse item, pois os respondentes com até 10 anos de profissão apresentam maior nível de estresse.

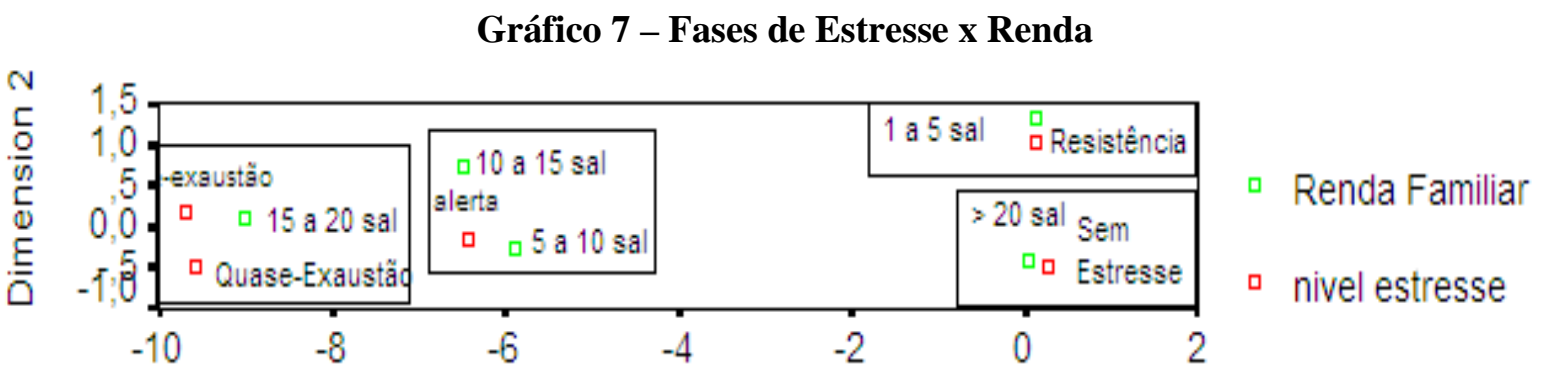

\section{Dimension 1}

Fonte: Dados da pesquisa.

O Gráfico 8 apresenta o tempo de atuação profissional com a fase de estresse. Os grupos que vão de 1 a 10 anos de profissão não apresentam estresse, os que vão de 10 a 15 anos apresentam-se na fase de resistência. 
Gráfico 8 - Fases de Estresse x Tempo de Atuação Profissional

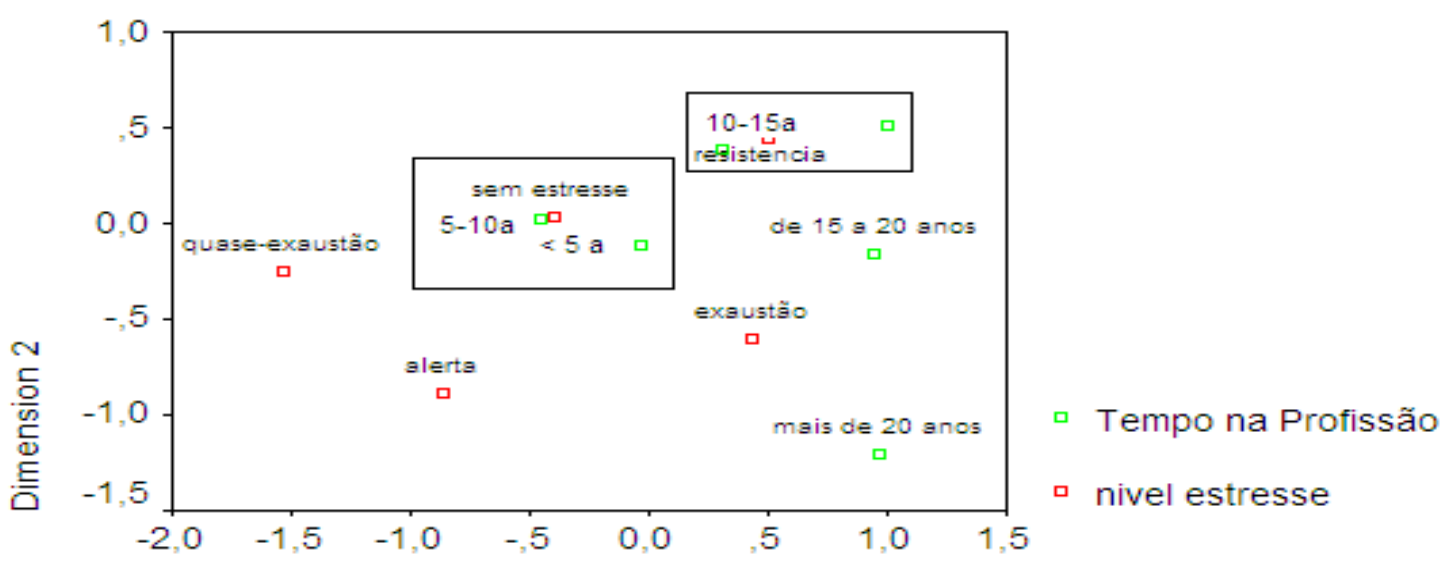

Dimension 1

Fonte: Dados da pesquisa.

No Gráfico 9, foi feita a análise da região do estado onde o contabilista trabalha e as fases de estresse. As pessoas que trabalham na região metropolitana do Rio de Janeiro estão entre a fase de resistência e a fase dos sem estresse. As regiões norte-fluminense e o litoral são as outras duas regiões onde há habitantes sem estresse.

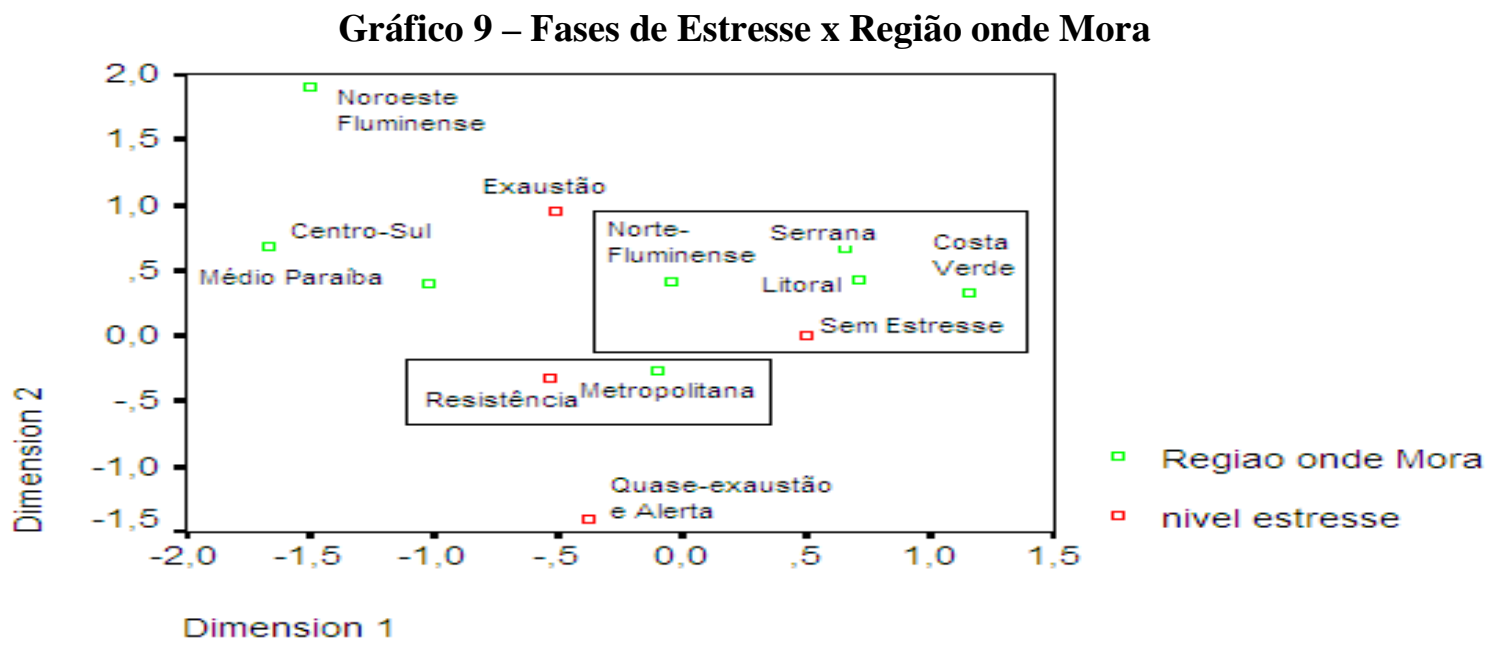

Fonte: Dados da pesquisa.

Por fim, utilizou-se a AC entre as diversas variáveis individuais e profissionais, a variável estresse, e chegou-se aos seguintes resumos do Quadro 2.

\begin{tabular}{|l|c|c|c|c|c|}
\hline \multicolumn{1}{l}{ Quadro 2 - Análise de Correspondência x Variáveis } \\
\hline Fase de Estresse & ALERTA & RESISTÊNCIA & $\begin{array}{l}\text { QUASE } \\
\text { EXAUSTÃO }\end{array}$ & EXAUSTÃO & $\begin{array}{l}\text { SEM } \\
\text { ESTRESSE }\end{array}$ \\
\hline Gênero & - & Mulheres & - & - & Homens \\
\hline Idade & - & $\begin{array}{c}\text { Acima de } 41 \\
\text { anos }\end{array}$ & - & - & Até 40 anos \\
\hline Estado Civil & - & Casado e União & - & Separado & Solteiro e \\
\hline
\end{tabular}


Análise do nível de estresse do profissional de Contabilidade

\begin{tabular}{|c|c|c|c|c|c|}
\hline & & Estável & & & Viúvo \\
\hline $\begin{array}{l}\text { Atividades } \\
\text { Domésticas }\end{array}$ & 0 hora & Mais 2horas & - & 0 hora & Até 2 horas \\
\hline Número de Filhos & com filho & sem filho & com filho & - & Sem filho \\
\hline Renda & 5 a 15 s.m. & 1 a 5 s.m. & 15 a 20 s.m. & 15 a 20 s.m. & $>20$ s.m. \\
\hline Tempo Pessoal & Às vezes & Muito Pouco & - & Nunca & $\begin{array}{l}\text { Muito } \\
\text { tempo }\end{array}$ \\
\hline Tempo na Profissão & - & 10 a 15 anos & - & - & $\begin{array}{c}\text { Até } 10 \text { anos } \\
\text { ou }>15 \\
\text { anos }\end{array}$ \\
\hline $\begin{array}{l}\text { Região onde } \\
\text { Trabalha }\end{array}$ & - & RJ & - & - & outra \\
\hline $\begin{array}{l}\text { Relacionamento } \\
\text { Social }\end{array}$ & - & $\begin{array}{l}\text { Nem satisfeito, } \\
\text { nem insatisfeito }\end{array}$ & - & $\begin{array}{c}\text { Muito } \\
\text { Satisfeito }\end{array}$ & $\begin{array}{l}\text { Satisfeito e } \\
\text { Insatisfeito }\end{array}$ \\
\hline
\end{tabular}

Fonte: Dados da pesquisa.

Nota-se, no Quadro acima, que as fases de estresse que mais apresentam respondentes são: fase de resistência e os sem estresse. Portanto, dos respondentes, a maioria se encontra ou desestressado ou na fase intermediária de estresse.

\section{Considerações Finais}

O principal fator para a escolha desse tema refere-se à importância do estudo do estresse para a sociedade atual. O objetivo geral consistiu em identificar o grau de estresse e os sintomas fundamentais que ocorrem nos profissionais de Contabilidade, relacionando-os com fatores individuais e profissionais em seu desempenho e os sintomas de estresse que apresentam.

O questionário foi dividido entre três aspectos, pois fornece uma medida objetiva dos sintomas de estresse.

Quanto ao primeiro aspecto, individual, chegou-se aos seguintes resultados: predomínio de mulheres sobre os homens, com faixa etária média dos respondentes de 33,4 anos. A maioria é casada, não possui filhos, gasta em média duas horas com as atividades domésticas e está satisfeita ou muito satisfeita com seus relacionamentos sociais. Já para o segundo aspecto, profissional, a maior parte recebe mais de dez salários mínimos, tem menos de dez anos de profissão e atua nas áreas pública $(51,11 \%)$ e privada $(23,57 \%)$, além de trabalhar na região metropolitana do estado do Rio de Janeiro. Por fim, os sintomas de estresse apresentados foram: fases de alerta, resistência, quase exaustão e sem estresse, predomínio dos sintomas físicos; já na fase de exaustão, predominaram os sintomas psicológicos.

Identificou-se que 50\% da amostra estudada não se enquadram em nenhuma das fases de estresse. A fase de resistência apresenta maior número de contabilistas estressados (35\%), seguido da fase de exaustão, que apresenta $13 \%$. Tanto a fase de alerta, quanto à fase de quase exaustão atingiram $1 \%$.

Este estudo não responde a todas as abordagens sobre estresse. Devem ser consideradas as limitações desta pesquisa, pois foram restritas àqueles profissionais contabilistas que estão no cadastro do CRC-RJ, tendo amostra de 443 respondentes. Com esse número, buscou-se comprovar a correspondência entre as variáveis. 

propõe-se:

Para a realização de novos estudos e continuidade da investigação desta pesquisa,

- Influência de fatores individuais como: gênero, idade, estado civil, número de filhos, tempo dedicado a atividades domésticas e a cuidados pessoais e o relacionamento pessoal em profissionais contábeis de outras unidades da Federação.

- Influência de fatores profissionais como: renda familiar, o tempo de atuação na profissão, o papel e as atividades desempenhadas, distribuição demográfica e se realizam ou não atividades complementares pessoal em profissionais contábeis de outras unidades da Federação.

- Avaliar o impacto do nível de estresse sobre o desempenho do profissional.

Por fim, deve-se frisar que todos os objetivos deste estudo podem ser replicados como modo a confirmar os resultados aqui alcançados.

\section{Referências}

ARANHA, R. N.; FAERSTEIN, E.; AZEVEDO, G.M.; WERNECK, G.; LOPES, C. S.. Análise de correspondência para avaliação do perfil de mulheres na pós-menopausa e o uso da terapia de reposição hormonal. Cad. Saúde Pública, Rio de Janeiro, v. 20, n. 1, p.100-108, jan./fev. 2004.

BRASIL. Lei n. 6.404, de 17 de dezembro de 1976. Dispõe sobre as Sociedades por Ações. Diário Oficial [da] República Federativa do Brasil, Brasília, DF, 17 dez. 1976.

FERACHIN, L. K. ; RANZI, P. ; GARIB, S. M. ; LOPES, S. A. "Ser melhor": conhecendo o stress, vivendo com qualidade de vida, um trabalho com policiais militares, 2004.

LAKATOS, E. M.; MARCONI, M. A. Fundamentos de Metodologia Científica. 1. ed. São Paulo. Ed. Atlas, 1985.

LIMONGI-FRANÇA, A. C.; RODRIGUES, A. L. Stress e trabalho: uma abordagem psicossomática. 2. ed. São Paulo: Atlas, 1999.

LIPP, M. E. N. Estresse emocional: a contribuição de estressores internos e externos. Revista Psiquiátrica Clínica, [S.1.], v. 24, n. 6, p. 347-349, 2001.

LIPP, M. E. N. Como enfrentar o stress. Campinas: Unicamp; São Paulo: Ícone, 1998.

LIPP, M. E. N. O inventário de Sintomas de Stress para Adultos de Lipp (ISSL). São Paulo: Casa do Psicólogo, 2000.

LIPP, M. E. N. Manual do inventário de sintomas de stress para adultos de Lipp (ISSL). São Paulo: Casa do Psicólogo, 2000.

LIPP, M. E. N. Pesquisas sobre stress no Brasil: saúde, ocupações e grupos de risco. 2. ed. Campinas, SP: Papirus, 2001.

LIPP, M. E. N. O stress está dentro de você. 5. ed. São Paulo: Contexto, 2003. 
LIPP, M. E. N. O Modelo Quadrifásico do Stress. In: LIPP, M. E. N. (Org.). Mecanismos neuropsicofisiológicos do stress: teoria e aplicações clínicas. São Paulo: Casa do Psicólogo, p. 207-202. 2003

LIPP, M. E. N.; TANGANELLI, M. S. Stress e qualidade de vida em magistrados da Justiça do Trabalho: diferenças entre homens e mulheres. Revista Psicologia: Reflexão e Crítica, Porto Alegre, v. 15, n. 3, p. 537-548, 2002.

MILSTED, J.; AMORIM, C.; SANTOS, M. Nível de Estresse em alunos de psicologia do período noturno. Congresso Nacional de Educação. PUC Paraná, Paraná. 2009.

PASSATI, I. C.; DIAS, M. R. Multiplicidade de papéis da mulher e seus efeitos para o bemestar psicológico. Psicologia: Reflexão e Crítica, [S.1.], v. 15, n. 2, p. 293-301, 2002.

PIOVESAN, A; TEMPORINI, E. R. Pesquisa exploratória: procedimento metodológico para o estudo de fatores humanos no campo da saúde pública. Revista Saúde Pública, v. 29 n. 4, p. 318-325, 1995.

ROMERO, S. M. T; OLIVEIRA, L. O; NUNES, S. C. Estresse no ambiente organizacional: estudo sobre o corpo gerencial. In: SEGET, Simpósio de Excelência em Gestão e Tecnologia, 4., 2007, Resende. Anais eletrônicos... Resende: [s.n.], 2007.

ROSSETTI, M. O. et al. O inventário de sintomas de stress para adultos de lipp (ISSL) em servidores da polícia federal de São Paulo. Revista Brasileira de Terapias Cognitivas, v. 4, n. 2, p. 108-120, 2008.

ROSSI, A. M. Autocontrole: nova maneira de controlar o estresse. 5. ed. Rio de Janeiro: Rosa dos Tempos, 2005.

SCARPARO et al. Estresse e vestibular como desencadeadores de somatizações em adolescentes e adultos jovens. Revista Psicologia e Argumento, v. 22, n. 55, p. 319-327, 2008 .

SEGATO et al. Estresse psicológico de velejadores de alto nível esportivo em competição. Revista Motricidade FTCD-CIDESD, v. 6, n. 3, p. 53-62, 2010.

SELYE, H. Stress: a tensão da vida. São Paulo: IBRASA. 1965.

SILLAS, E. P. Mulheres Contabilistas: um estudo do nível de estresse das profissionais atuantes no Estado do Paraná. Dissertação (Mestrado) - Pontifícia Universidade Federal do Paraná, Curitiba, 2011.

SMITH, A.; BRICE, C.; COLLINS, A.; MATTHEWS, V.; McNAMARAET, R. The scale of occupational stress: a further analysis of the impact of demographic factors and type of job. [S.l.]: Centre for Occupational and Health Psychology, School of Psychology, Cardiff University, 2000.

TANGANELLI, M. S. L. Mulher chefe da família: perfil, estudo e tratamento do stress. 2001. 224 f. Tese (Doutorado em Psicologia Clínica) - Pontifícia Universidade Católica, Campinas, 2001.

VIEIRA, S. S. C. Avaliação de programas de educação continuada: análise da percepção do aluno e do seu modelo de decisão para escolha de programas de especialização para executivos no Brasil. Tese de Doutorado. USP. São Paulo, 2009. 
WISNIEWSKI, S. W.; STEFANO, S. R. Estresse dos Bancários de Irati: um estudo de caso. Revista Eletrônica Lato Sensu, [S.1.], ano 3, n. 1, p.1-22, 2008. 